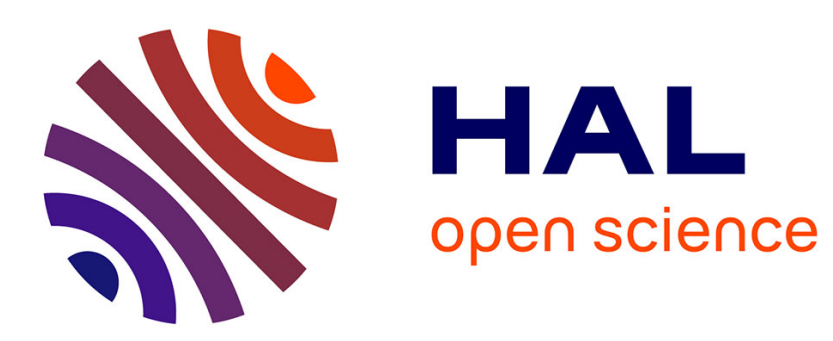

\title{
USE OF THERMAL INFRARED REMOTE SENSING FOR WATER BUDGET STUDIES
}

\author{
C Ottle, Y Sucksdorff, M Ben Mehrez
}

\section{To cite this version:}

C Ottle, Y Sucksdorff, M Ben Mehrez. USE OF THERMAL INFRARED REMOTE SENSING FOR WATER BUDGET STUDIES. Advances in Space Research, 1991, 11 (3), pp.163-167. hal-03299111

\section{HAL Id: hal-03299111 \\ https://hal.science/hal-03299111}

Submitted on 27 Jul 2021

HAL is a multi-disciplinary open access archive for the deposit and dissemination of scientific research documents, whether they are published or not. The documents may come from teaching and research institutions in France or abroad, or from public or private research centers.
L'archive ouverte pluridisciplinaire HAL, est destinée au dépôt et à la diffusion de documents scientifiques de niveau recherche, publiés ou non, émanant des établissements d'enseignement et de recherche français ou étrangers, des laboratoires publics ou privés. 


\title{
USE OF THERMAL INFRARED REMOTE SENSING FOR WATER BUDGET STUDIES
}

\author{
C. Ottlé, ${ }^{*}$ Y. Sucksdorff** and M. Ben Mehrez* \\ ${ }^{*}$ CNET/CRPE-CNRS, 38/40 Rue du Général Leclerc - 92131 \\ Issy-les-Moulineaux, France \\ **National Board of Waters and the Environment, BP 250, \\ 00101 Helsinki, Finland
}

\section{Abstract}

We have developed in our group an interface model which simulates the thermal and hydraulic exchanges between the soil, the vegetation and the atmosphere and estimates the energy fluxes at the surface. This model has been shown to be able to assimilate thermal infrared and microwave data for calibration of some surface parameters. It has been used over different regions and different periods of the year. Recent results will be presented.

A first study in the frame of the HAPEX-MOBILHY experiment,(1985-1986) has shown that satellite thermal infrared and visible data may be used to calibrate the soil and the vegetation functional parameters of the model and estimate during the year either the soil moisture in the surface layer or the water available in the root zone at a scale compatible with the grid of an hydrological model.

The second study is the application of this method over a Finnish watershed continuously over the month of July 1988. The total evapotranspiration has been estimated and compared to the estimate given by a water balance method.

\section{INTRODUCTION}

Knowledge of areal evapotranspiration at regional scale is strongly needed for hydrological studies and specially for hydrological modeling. It is well-known that hydrological models do not succeed to simulate realistically the soil moisture in the surface layer, particularly during summer months when the drying out is too large. This drawback leads to the impossibility to simulate correctly the floods at the precipitation recovery. Thanks to the spatial observations providing large-scale measurements, it is now possible to use remote sensing data to evaluate energy and momentum fluxes between soil, vegetation and atmosphere, and then to assimilate real evapotranspiration or soil moisture in hydrological models to monitor water exchanges between the soil layer and the atmosphere.

The method is based on the use of models simulating the exchanges at the soil interface and able to assimilate the infrared surface temperatures measured by satellites. In this way, if the atmospheric and surface parameters are known, the energy and hydraulic budgets at the surface can be modeled and surface temperature estimated from infrared remote sensing can be used to estimate one surface parameter which would be unknown in the model and which could be for example the soil moisture. This methodology has already been successfully applied locally in the case of bare soils $/ 1,2 /$ and in the case of a dense vegetation $/ 3 /$, but until now, has never been validated at a larger scale and on a long time period.

We present here two studies. The first one is part of the HAPEX-MOBILHY experiment in South-Western France. The inversion model has been calibrated locally on different soils and on different vegetative conditions before being applied on the whole area $\left(100 \times 100 \mathrm{~km}^{2}\right)$. The soil moisture have then been estimated and compared with the same parameters modeled by a hydrological model.

The second study was carried out over a whole watershed (about $1225 \mathrm{~km}^{2}$ ), in South-Western Finland to show that our inversion method can be used to monitor water budgets during periods in the order of one month. The modelled evaporation has been compared with that estimated with the water balance method.

\section{The surface temperature / surface fluxes inversion model}

Our model is based on the formalism of / 4/. It calculates the surface fluxes, surface temperature and soil moisture from the knowledge of the atmospheric forcing and from the characteristics of soil and vegetation. The soil is represented as a two layers system modified by $15 /$, where the thermal and hydraulic transfers are described by three important parameters : thermal inertia, hydraulic diffusivity and limit evaporation. The vegetation is described by one single foliage layer with negligeable heat capacity, shielding more or less completely the ground. The most sensible parameters characterizing the canopy in the model are : the vegetation height, the Leaf Area Index and the minimum resistance to evaporation which all depend on the type of cover and on its state of maturity.

Before the model could be run, all these parameters have to be fixed for each different surfaces available in the region under study. All the soil coefficients depend on soil texture and moisture and can be adjusted with usual functions found in the literature. But, if soil measurements and soil fluxes are available at the same time, they can be 
estimated directly. This was the case during HAPEX experiment and so this method has been applied over the region where all the measurements necessary to calibrate our model have been made on different sites.

\section{HAPEX-MOBILHY (HM) study}

\section{The HM experiment}

This program was designed to measure the surface fluxes and specially the evaporation at different time and space scales over a hundred kilometers square in South-Westem France. The first results of the experiment are described in $16 \%$.

During a Special Observing Period in 1986 (May, $7^{\text {th }}$ - July,15th), micrometeorological, soil and biological measurements have been made at twelve different sites where SAMER ( Systeme Automatique de Mesure de l'Evapotranspiration Régionale) equipments were implemented. At each of these sites, wind, temperature, relative humidity, radiation fluxes and ground heat flux were collected every $15 \mathrm{mn}$. The sensible heat flux is then calculated via the flux-gradient relationship and the latent heat flux is estimated by balancing the surface energy budget. The vegetation height and the local soil water profiles were also measured every week.

With all these data, it has been possible to calibrate all the surface parameters of the model and to simulate the real surface fluxes during the whole vegetative period.

\section{Local validation of the surface model .}

The soil parameters of the model have first been calibrated at the beginning of the SOP when most of the sites were bare soils. All the input parameters of the model were measured as well as the sensible heat flux. At one site called "Castelnau", the surface temperature was also measured with an infrared radiometer. So, by comparing the sensible heat flux and the surface temperature modeled to the measured ones for different days, the three most sensible parameters of our model ( thermal inertia, hydraulic diffusivity and limit evaporation) have been estimated and verified over different sites with same soil texture and on other days.

Over fully vegetated sites, as the Leaf Area Index and the height of the canopy were measured, the last parameter to calibrate was the minimum resistance to evaporation. In the same way as for bare soils, it has been estimated for different maturity states by adjusting the fluxes.

Then, the model and the calibrated coefficients have been validated during the intermediate period on partial canopies where the evaporation from the vegetation and from the soil surface are comparable.

All these results are detailed in $7,8 /$ and we just present here for these three types of surfaces, the comparison between the modeled and measured sensible heat flux for two different soil textures ( sand and loam) and two different vegetation (corn and oat) on the $16^{\text {th }}$ of June , validation day, where the modelled values are independant of the measurements(Figure1).

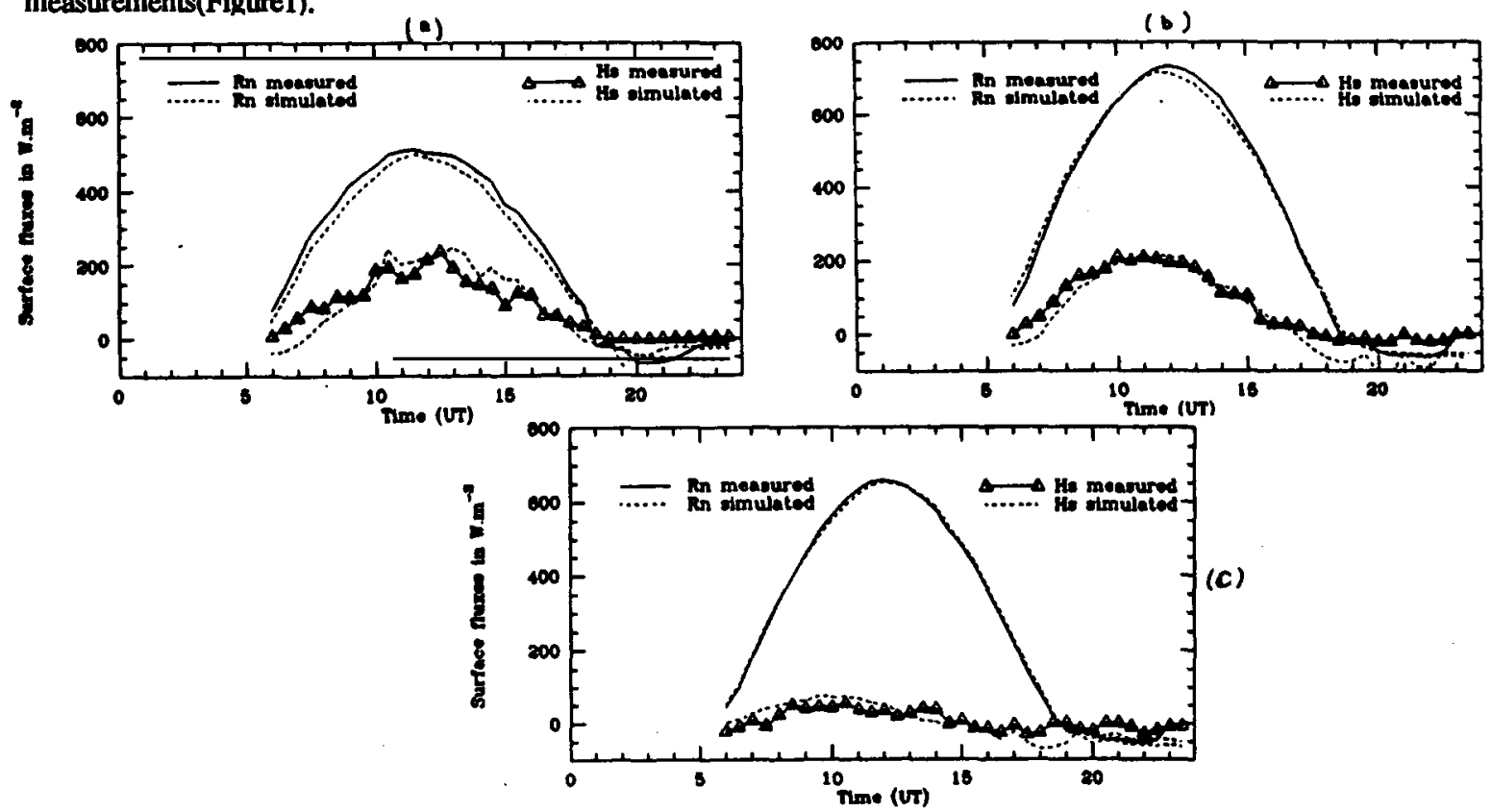

Fig. 1 : Comparison of measured and simulated daily sensible heat flux Hs in three cases : a) over a loamy bare soil , b) over a partial canopy of maize on a sandy soil , c) over a dense canopy of oat on a sandy soil , for the $16^{\text {th }}$ of June 86 . (Rn is net radiation). 


\section{Follow up of the regional hydraulic budget on HM region}

If one wants to follow precisely the hydraulic budget over a whole watershed, it is necessary to use a hydrological model to simulate the surface and the underground flows. Over the HM region, an hydrological model 19,10 / has been calibrated and run during the two years of the experiment (1985-1986). The model is spatially distributed with a grid size of $5 \mathrm{~km}$. The input parameters are the precipitation and potential evaporation and the model simulates the evolution of soil moisture and the streamflows at the outlets.

As our surface model is able now to simulate the fluxes on all the types of surfaces available over the HM square, it can be used to inverse the soil moisture at the satellite pixel size(or the hydrological model grid size), on the whole region and for all the days for which the surface temperature can be estimated from satellite thermal infrared data. Then, the estimated values can be introduced in the hydrological model to reinitialise it, each day when a cloudless satellite image is available.

During the two years of the HM experiment, at least one cloudless image per week from NOAA9-AVHRR over the region have been selected, and up to now, just the images taken during the SOP have been treated. Surface temperature was calculated from Channel $4(10.5-11.3 \mathrm{~mm})$ corrected from atmospheric absorption with a radiative tranfer model (LOWTRAN6) where the atmosphere is prescribed by radiosoundings data.

After determination of the soil texture of each mesh of the hydrological model, the soil parameters of the interface model are fixed following the results of the local adjustements. The vegetation parameters must be determined at the same scale. The only way to do it, is to use the Normalised Difference Vegetation Index (NDVI), which is a combination of visible and near infrared reflectances, and is proportional to the chlorophyll density. From this index and with the rough knowledge of the type of plant, the Leaf Area Index and the height of the vegetation have been estimated for each pixel of the satellite image. Figure 2 shows the NDVI calculated over South-Western France for one day ( $10^{\text {th }}$ of July 86 ). As it can be seen,the highly vegetated areas like the Landes forests have bigger values than the urban areas and non-agricultural zones.

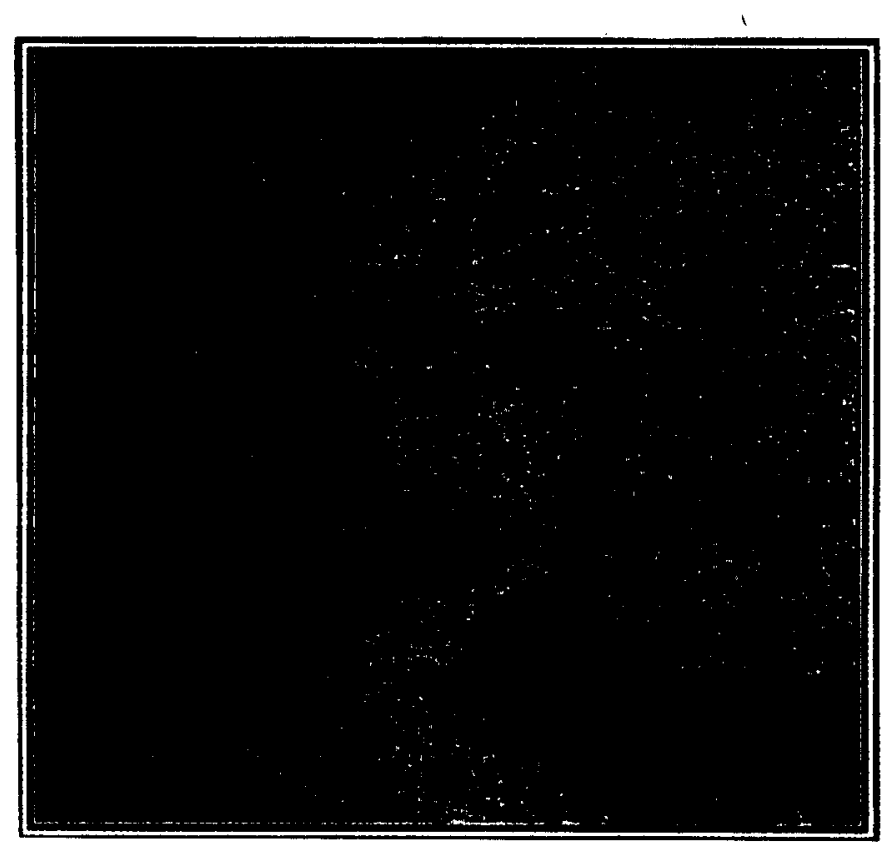

Fig. 2 : NDVI calculated over South-Western France on the $10^{\text {th }}$ of July 86 . Values are in percentage. The color scale goes from black to red for high values.

Finally, the soil moisture in the root zone (about 1 meter deep) has been estimated from the surface temperature on each mesh of the hydrological model and compared to the simulated one. Generally, as it can be seen on Figure 3 for 
the $10^{\text {th }}$ of July, the inversed soil moisture is larger than the modeled one specially in the South part of the square, and more homogeneous. It seems to be an improvement as the largest drawback of the model is to dry the surface layer unrealistically. These very preliminary results must now be confirmed by comparing the time evolution of the satellite inversed soil moisture to the soil moisture profiles measured locally.

Afterwards, the inversed soil moisture and the real evaporation will be assimilated regularly to reinitialise the hydrological model.

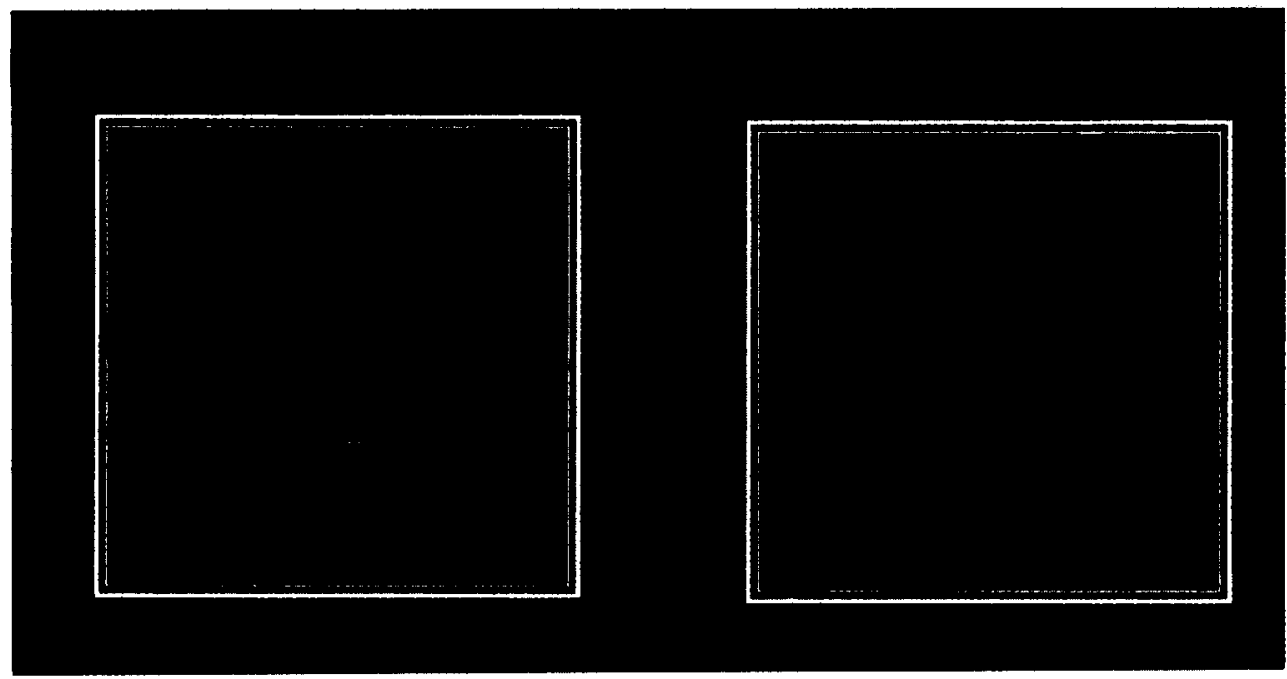

(a)

(b)

Fig. 3 : Soil moisture over the H-M square modeled by the hydrological model (a), compared with the one inversed by the surface model (b) for the $10^{\text {th }}$ of July 86 . The color scale goes from black to red.

\section{ESTIMATION OF REAL EVAPORATION OVER A FINNISH WATERSHED}

The soil/vegetation/atmosphere model has also been used to estimate the total evaporation over the Eurajoki river basin and its two sub-basins in South-Western Finland during the entire month of July. The model has been first calibrated with the existing measurements on all the different types of soils and vegetation existing on the area and then run for the whole month of July 1988.

\section{Model calibration}

The studied region is mostly covered by forests (about 50\%) and agricultural areas (about 30\%). The lake area varies between 0 and $25 \%$ depending on the subwatershed In the agricultural areas, the soil is mostly heavy clay and in the other open areas, the soil is generally sand. During the summer months, the region is fully vegetated. Then, the most sensible parameters of the interface model are the vegetation ones. They have been fixed with the help of land uses maps and satellite data.

For the determination of the land-use parameters, LANDSAT-TM images and digitalized map data have been used. To determine the Leaf Area Index and the minimum resistance to evaporation, NDVI and surface temperature cstimated from NOAA9/AVHRR images were treated.

As the NDVI was nearly the same on three images spread over the month, the LAI and the height of the vegetation were kept constant all along the simulation. We found LAI equal 4 and $\mathrm{h}$ equal $1 \mathrm{~m}$ to be representative of the mean conditions in agricultural lands in the region.All these results are already described in $/ 11 /$.

\section{Result of the montbly modelisation} of July 88 .

The model has been run for the two main soil types for open areas in the Eurajoki river basin for all the month

The total cumulative evapotranspiration has then been calculated for the three river basins as a weighted mean of evapotranspirations from different soil types. As soil is generally clay in the agricultural areas and sand in the other open areas, and assuming that forest evaporate at potential rate, the total modeled evapotranspiration is presented for the three river basins in Table 1. It can be compared with the one estimated by the water balance method. The results show very little differences between the two methods and demonstrate the potentiality of the methodology. But this work must now be done on longer time periods during which ground measurements and satellite will be available to test the accuracy of the model. 
TABLE 1. Results of monthly areal evaporation calculations for the Eurajoki river basin and its two subbasins. WB : evapotranspiration with water balance method, EP : potential evaporation, and Etot is the total modelled evapotranspiration from the corresponding river basin.

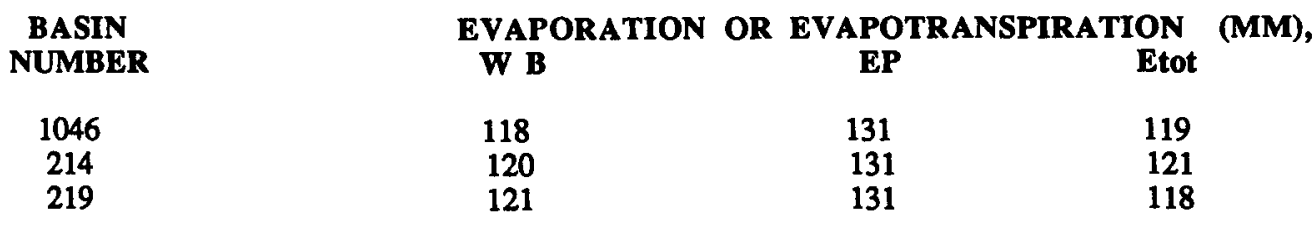

\section{CONCLUSION}

In all these studies, we have tried to show that remote sensing may contribute efficiently to soil water budgets monitoring. Thanks to their high resolution and repetitivity, meteorological satellite can be used to provide surface parameters of primary importance for atmospheric or hydrological models at a scale compatible with their grid of calculation and regularly in time.

The knowledge of evaporation or soil moisture at regional scale will improve greatly the follow up of surface water budgets and could certainly help in irrigation control and agricultural monitoring.

\section{Acknowledgements}

This work was supported by Centre National de la Recherche Scientifique, Centre National d'Etudes des Télécommunications, the Academy of Finland and the Ministère des Affaires Etrangères. The authors would like to thank all their colleages at C.R.P.E. and all the people who contributed to provide the data for the two experiments.

\section{REFERENCES}

1. Carlson, T. N., 1986: " Regional scale estimates of surface moisture availability and thermal inertia". Remote sensing reviews, $1,197-247$.

2. Soarès, J. V. ,R. Bernard, O.Taconet, D.Vidal-Madjar and A. Weill 1988 : "Estimation of Bare soil Evaporation from airborne measurements". J. of Hydro. ,99, 281-296

3. Taconet, O., R. Bemard, and D. Vidal-Madjar, 1986 : " Evapotranspiration over an agricultural region using a surface flux / temperature model based on NOAA-AVHRR data". J.Climate Appl. Meter.,25, 284-307.

4. Deardorff, J.W. 1978: " Efficient prediction of ground surface temperature and moisture, with inclusion of a layer of vegetation". J. Geophys. Res. ,83(C4) 1889-1903.

5. Bemard, R., J.V. Soares and D.Vidal-Madjar, 1986 : "Differential bare field drainage properties from airborne microwave observation". Water Resour.Res.,22(6),869-875.

6. Andre, J.C. and collaborators, 1988: "HAPEX-MOBILHY : First results from the Special Observing Period". Ann. Geophys., 6, 477-492.

7. Ben Mehrez, M., O. Taconet, D. Vidal-Madjar and Y. Sucksdorff, 1990: "Calibration of a fluxes model over bare soils during HAPEX-MOBILHY experiment". Submitted to Agric. For. Meteor.

8. Ben Mehrez, M., O. Taconet, D. Vidal-Madjar and C. Valencogne, 1990: "Estimation of canopy stomatal resistance during HAPEX-MOBILHY experiment". Submitted to Agric. For. Meteor.

9. Girard, G. and Boukerma, B., 1985 : "Projet HAPEX-MOBILHY, Calage du Modele Hydrologique Rapport LHM/RD/85/110, (available from CIG, 35 rue Saint-Honore,77305 Fontainebleau Cédex,France )

10 Ottle, C., D. Vidal-Madjar and G. Girard, 1989 : " Remote Sensing Applications to Hydrological Modeling ". J. Hydrology 105, 369-384.

11. Sucksdorff, Y. and C. Ottlé, 1990 : " Application of satellite remote sensing to estimate areal evapotranspiration over a watershed". J. Hydrology, in press 